\title{
Suspected breast implant rupture: our experience, recommendations on its management and a proposal for a model of informed consent
}

\author{
Nicola Zingaretti ${ }^{1,2}$ (D) Daniele Fasano ${ }^{3} \cdot$ Franz W. Baruffaldi Preis ${ }^{4} \cdot$ Carlo Moreschi $^{5} \cdot$ Silvia Ricci $^{6}$. \\ Samuele Massarut ${ }^{2} \cdot$ Francesco De Francesco $^{7}$. Pier Camillo Parodi ${ }^{1,8}$
}

Received: 29 October 2019 / Accepted: 9 December 2019 / Published online: 20 December 2019

(C) The Author(s) 2019

\begin{abstract}
Background Implant rupture may be detected by physical examination, ultrasound or magnetic resonance imaging (MRI); the majority of silicone implant ruptures are clinically undetectable. The absence of guidelines for behaviour in the face of a suspected implant rupture often entails sending these patients for prosthetic revision surgery rather than carrying out in-depth radiodiagnostics to confirm implant rupture. The aim of this paper is to report our multicentric experience, to indicate the correct diagnostic-therapeutic procedure and to propose a model of informed consent.

Methods We conducted a multicentric retrospective analysis of 183 women submitted to prosthetic revision surgery due to radiological diagnosis of suspected implant rupture after breast augmentation or post-mastectomy reconstruction, admitted to three different Plastic Surgery Departments between 2002 and 2018. We correlated surgical findings with purpose of examination, symptoms, physical examination, imaging and device specifications.

Results Two hundred and twenty-one explanted implants were preoperatively suspected as ruptured. One-third were intact and unjustifiably explanted. US associated with MRI evaluation was the most accurate method. Patient's age, comorbidities, smoking, medications, symptoms presented, implant duration and volume did not correlate with implant rupture.

Conclusions Our study confirms that the association of US and MRI represents the mode of diagnosis with fewest false positives. Given the high number of errors associated with suspected intracapsular implant rupture, it seems necessary to submit an appropriate and specific informed consent that takes into account the emotional component and clearly and completely explains the possible alternatives and complications associated with possible prosthetic revision surgery.

Level of evidence: Level III, risk/prognostic study
\end{abstract}

Keywords Informed consent $\cdot$ Breast implant rupture $\cdot$ Breast reconstruction $\cdot$ Breast augmentation $\cdot$ Imaging of breast implant

Electronic supplementary material The online version of this article (https://doi.org/10.1007/s00238-019-01610-1) contains supplementary material, which is available to authorized users.

Nicola Zingaretti

zingarettin@gmail.com

1 Clinic of Plastic and Reconstructive Surgery Academic Hospital of Udine, Department of Medical Area (DAME), University of Udine, c/o Ospedale "S. Maria della Misericordia", piazzale santa maria della misericordia 15, 33100 Udine, Italy

2 Breast Surgery Unit, CRO, National Cancer Institute, Aviano, Italy

3 Casa di Cura Villa Toniolo, 40122 Bologna, BO, Italy
4 Reap.U.O. Chirurgia Plastica, IRCCS Ospedale Galeazzi, Bruzzano, Milan, Italy

5 Department of Medical and Biological Sciences, Section of Forensic Medicine, University of Udine, Udine, Italy

6 U.O.S Chirurgia Plastica Ospedale Bellaria, Bologna, Italy

7 SODC Chirurgia Ricostruttiva e Chirurgia della Mano, AOU Ospedali Riuniti, Ancona, Italy

8 Research and Training Center in Regenerative Surgery, Accademia del Lipofilling, Ancona, Italy 


\section{Introduction}

Breast augmentation is the most commonly performed surgical procedure in aesthetic plastic surgery and implant-based breast reconstruction is the most popular technique worldwide in post-mastectomy patients [1-6].

According to the American society of plastic surgeons, about 400,000 women in the USA alone undergo cosmetic or reconstructive breast augmentations annually, making the insertion of silicone implants the most frequently performed intervention in plastic surgery [7]. In 2017, the total amount of aesthetic breast augmentation surgeries in USA was 333,392, an increase in comparison with $2016(312,774)$. In 2018, approximately 51,000 implants were used in Italy, $63 \%$ for aesthetic reasons and $37 \%$ for reconstructive reasons.

Implant rupture is one of the most important complications of implant reconstruction, together with capsular contracture. Implant rupture that can occur from 10 to 15 years from implantation is rarely associated with a traumatic event and represents the most common cause of prosthesis removal $[8,9]$.

Symptoms such as change in breast shape, size or firmness, capsular contracture, palpable lumps or breast pain may lead to patient evaluation for implant rupture. Clinically significant signs or symptoms are not presented by most breast implant rupture patients, who are classified as having "silent" ruptures. In more than $50 \%$ of cases, it is not detected during clinical examination. The imaging diagnosis of the rupture of the mammary implant is a frequent consultation and a diagnostic challenge.

In extracapsular rupture, both the implant shell and the fibrous capsule are breached, with macroscopic silicone leakage into the surrounding tissues or lymph nodes; in the literature, a high rate of correspondence is reported when breast ultrasound is used to confirm an extracapsular rupture. As already reported by numerous authors, the diagnosis of extracapsular rupture has less false positives than intracapsular rupture, both when ultrasound and MRI are used [10-12].

In the case of intracapsular rupture, the implant shell is breached without macroscopic silicone leakage beyond the intact fibrous capsule. Although there are typical signs at both ultrasound and MRI $[10,11]$, there is not a high match between diagnosis and the actual clinical picture.

The diagnosis of prosthetic rupture may not always appear as a frank rupture and a diagnosis of "suspected rupture" is often possible; in such cases, a further in-depth diagnostic examination is not always required, but the patient may be advised to consult the plastic surgeon.

The patient does not always receive exhaustive information about possible treatment options, the number of false positives and the risks associated with possible prosthetic revision surgery.

It is therefore of primary importance to establish an adequate diagnostic-therapeutic procedure to be followed and, from a medical-legal point of view, a specific and detailed informed consent based on evidence-based medicine.

\section{Methods}

We performed a multicentric retrospective analysis of 183 patients who underwent surgical removal of the prosthesis due to implant rupture diagnosis between November 2002 and January 2018 in 3 different Plastic Surgery centres (Centre-North, North-East and Central Italy).

Our research focussed on possible associations between implant rupture and implant specifications. We examined the medical history and symptoms of the patients, comparing the main purpose of radiological investigation and physical examination at presentation, as well as the side presenting the ruptured implant, radiological, surgical and pathological data.

The study followed the principles of the Helsinki declaration and was approved by the local ethics committee.

\section{Imaging}

Our study included women who consulted our outpatient clinics with a radiological diagnosis of suspected breast implant rupture. We analysed 221 prostheses.

These patients underwent a radiological diagnostic examination for different reasons, such as follow-up/control, pain or discomfort, deformation or redness or swelling after trauma.

US and MRI examinations were performed in different radiodiagnostic centres and were analysed by a radiologist experienced in breast imaging without previous knowledge of the results of each method and blinded to surgical results.

The results regarding the integrity of the prostheses that were obtained at the time of the radiodiagnostic investigation were classified as follows:

- normal implant when the shell presented without loss of continuity or in the absence of typical signs of prosthetic rupture

- $\quad$ suspected prosthetic rupture when the prosthetic contour was altered in the absence of signs of pathognomonic prosthetic rupture.

- frank rupture of the prosthesis when the shell showed a loss of continuity with the release of silicone from the implant

This category (implant rupture) was divided into an intracapsular rupture (when the silicone remained defined by the fibrous capsule), an extracapsular rupture (when the silicone was present outside the fibrous capsule in the surrounding breast tissue) and intra-extracaspular rupture (when there were both together). 
Normally, asymptomatic patients were diagnosed with suspected rupture by ultrasound at a normal follow-up check. Patients with symptoms or following trauma underwent MRI directly.

For patients with ultrasound diagnosis of suspected prosthetic rupture, the radiologist recommended an in-depth examination by MRI or a visit to the plastic surgeon.

\section{Clinical examination}

During the interviews, we asked the women about their medical history, focussing on comorbidities, chronic medications, smoking and the age at which they had the implant. Among the symptoms reported, that led them to consult their doctor to be assessed for possible implant rupture, were breast pain, breast deformation or discomfort. We also documented implant data, including the manufacturer, duration, shape, texture, size and plane of augmentation.

All patients underwent a general physical examination including manual examination and measurement of the breast, while we looked for any signs of possible implant rupture.

We rated the overall aesthetic result and documented any surgical complications such as capsular contracture, asymmetry, palpability of the implant and enlargement of the axillary lymph node. Photographic documentation was also produced, with anterior and oblique views of the patients standing erect.

After informing the patient about the possible diagnosis and possible solutions, explaining the pros and cons of the intervention, the patients were placed on the waiting list with top priority for prosthetic revision. Written informed consent was obtained in all cases.

\section{Surgical findings at explantation}

After removal, the implants were examined for rupture, classifying them as ruptured or intact. Implants were considered normal when the elastomeric envelope was complete without perforations, also including a silicone gel layer because of bleeding, while implants in which the elastomer shell presented a lack of continuity were considered ruptured. No implants suffered damage during removal. As requested by the manufacturer, the removed implants were sterilised and returned for further examination.

Capsule irregularities were documented and, when present, a capsular biopsy was sent for pathological examination.

\section{Results}

Patients' demographics are reported in Table 1.

The mean age for breast augmentation in women was 42.6 years (IQR 18-74 years) and the mean age at which breast implant rupture was detected was 54.2 years (IQR $27-86$ years).

Seventy-four women underwent breast reconstruction after mastectomy due to breast carcinoma.

Fifty-four patients were smokers and sixty-nine patients take drugs.

As we can see in Table 2, the mean duration of implant was 14.1 years (IQR 3-38). Mean implant volume was $329.3 \mathrm{cc}$ (IQR 120-600).

Implant duration and volume were not statistically correlated with increased rupture rate. Most implants were round; the plane of augmentation was submuscular in most of the patients.

Eighty-nine percent of the prostheses were single lumen (all silicone implants).

The most frequent reasons for these patients to have a radiological examination were for control/follow-up (56\%), for the presence of deformity-asymmetry and redness $(25 \%)$, for pain and discomfort (15\%) and following accidental trauma at the breast level $(4 \%)$.

During the visit with the plastic surgeon, the symptoms complained of by patients were pain and discomfort (33\%), breast deformation (26\%) and redness (5\%); $36 \%$ of the patients reported no symptoms.

For radiological diagnosis, ultrasound alone was used in $51 \%$ of patients, MRI in $26 \%$, and in $23 \%$ of patients MRI was associated with ultrasound diagnosis.

In 138 cases, a radiological diagnosis of suspected intracapsular rupture was made, in 68 cases of extracapsular rupture and in 15 cases of intracapsular and extracapsular rupture.

One hundred and forty-eight implants were found to be ruptured during surgery and 73 without rupture at explantation.

Finally, there were no late seromas (defined as $20 \mathrm{cc}$ of periprosthetic fluid 6 months after the augmentation mammoplasty) and none of the capsules sent for pathological examination was positive for breast carcinoma or anaplastic large cell lymphoma (ALCL).

\section{Discussion}

In 2016, Lotan et al. reported their experience with 109 cases of implants removed following the diagnosis of suspected implant rupture [12]; in more than one-third of cases, the implants were not ruptured at removal and had therefore been unjustifiably removed.

In the literature, this is the largest case study of suspected implant rupture.

In this sense, our multicentric work confirms what was previously found: the number of implants removed that did not show any rupture was $33 \%$. This figure is not uniform in 
Table 1 Patient demographics

\begin{tabular}{|c|c|c|c|c|}
\hline Hospital & Centre 1 & Centre 2 & Centre 3 & Total \\
\hline No. of patients & 62 & 64 & 57 & 183 \\
\hline $\begin{array}{l}\text { Mean patient age at breast } \\
\text { augmentation (range) }\end{array}$ & $\begin{array}{r}47.3 \text { years } \\
(19-74)\end{array}$ & $\begin{array}{r}42.7 \text { years } \\
(18-53)\end{array}$ & $\begin{array}{r}37.8 \text { years } \\
(19-49)\end{array}$ & 42.6 years \\
\hline $\begin{array}{l}\text { Mean patient age at which breast } \\
\text { implant rupture was detected } \\
\text { (range) }\end{array}$ & $\begin{array}{r}56.4 \text { years } \\
(27-86)\end{array}$ & $\begin{array}{r}51.1 \text { years } \\
(33-71)\end{array}$ & $\begin{array}{r}55.1 \text { years } \\
(35-80)\end{array}$ & 54.2 years \\
\hline \multicolumn{5}{|l|}{ Comorbidities } \\
\hline None & $31 / 62(50 \%)$ & $48 / 64(75 \%)$ & $29 / 57(51 \%)$ & $\begin{array}{r}108 / 183 \\
(59 \%)\end{array}$ \\
\hline \multicolumn{5}{|l|}{ Patients with comorbidity } \\
\hline - History of breast cancer & 48 & 6 & 20 & 74 \\
\hline • Hypertension & 11 & 8 & 8 & 27 \\
\hline - Diabetes mellitus & 4 & 3 & 2 & 9 \\
\hline - Hypothyroidism & 3 & 2 & 4 & 9 \\
\hline - Fibromyalgia & 1 & 0 & 0 & 1 \\
\hline - Celiac & 2 & 2 & 1 & 5 \\
\hline \multirow[t]{2}{*}{ - Other } & 3 & 4 & 6 & 13 \\
\hline & $31 / 62(50 \%)$ & $16 / 64(25 \%)$ & $28 / 57(49 \%)$ & $\begin{array}{l}75 / 183 \\
(41 \%)\end{array}$ \\
\hline \multicolumn{5}{|l|}{ Smoking } \\
\hline - Yes & $19 / 62(31 \%)$ & $20 / 64(31 \%)$ & $15 / 57(26 \%)$ & $\begin{array}{l}54 / 183 \\
(30 \%)\end{array}$ \\
\hline • No & $43 / 62(69 \%)$ & $44 / 64(69 \%)$ & $42 / 57(74 \%)$ & $\begin{array}{r}129 / 183 \\
(70 \%)\end{array}$ \\
\hline \multicolumn{5}{|l|}{ Drugs } \\
\hline - None & $36 / 62(63 \%)$ & $48 / 64(75 \%)$ & $30 / 57(53 \%)$ & $\begin{array}{r}114 / 183 \\
(62 \%)\end{array}$ \\
\hline - Steroid treatment & $2 / 31$ & $3 / 16$ & $2 / 27$ & $69 / 183$ \\
\hline - Other & $24 / 31$ & $14 / 16$ & $25 / 27$ & $(38 \%)$ \\
\hline
\end{tabular}

the three centres taken into account: in fact, the second hospital (Centre-North) showed a lower number of false positives (20\%). This may be due to the increased number of diagnoses of suspected extracapsular ruptures, which we know have fewer false positives [10-16].

The first centre (North-East), on the other hand, showed a higher false positive rate than the others (40\%); this can be justified by the use of ultrasound alone (in $55 \%$ of cases) as a diagnostic method in a sample of patients who had mostly implants below the muscle (97\%), therefore less easily assessable than subglandular ones.

In the three study centres, ultrasound (51\%) was the most commonly used diagnostic method. This choice is related to the reason why these patients underwent the radiodiagnostic examination: in more than half of the patients $(56 \%)$, it was performed for annual follow-up/control. In these asymptomatic patients, the least expensive screening method was chosen; breast implants were then removed without further radiodiagnostic examination (MRI). Most of the implants removed and found intact had been evaluated by ultrasound alone $(42 \%)$.
Only in $23 \%$ of patients was the combination of ultrasound and MRI used for diagnosis.

The overall accuracy for magnetic resonance imaging was $94 \%$, whereas that for ultrasound was $72 \%$ [17, 18]. Although MRI has a higher specificity and sensitivity and is considered by many to be the method of choice in such patients [17], it still has false positives.

In this sense, our work confirms what is already present in the literature $[12,15,17]$ : the number of false positives decreases in cases where ultrasound and MRI are associated.

There is a significant cost difference between ultrasound and MRI, which tends to drive clinical decision making. The choice of technique mostly depends on the surgeon's preference, as there is currently no general agreement in favour of MRI screening when implant rupture is suspected [18]. There is a more controversial approach to asymptomatic implant rupture, preferring a "watchful waiting" strategy. Exchanging the implants of an asymptomatic women, whose breasts have a soft and satisfactory appearance, exposes them to the risk of potential complications resulting from surgery. In the case of cosmetic breast implants, the statistics indicate that the risk is low; 
Table 2 Implant specifications, symptoms and surgical plane of augmentation

\begin{tabular}{|c|c|c|c|c|}
\hline $\begin{array}{l}\text { Hospital } \\
\text { Implants suspected of rupture }\end{array}$ & $\begin{array}{l}\text { Centre } 1 \\
73\end{array}$ & $\begin{array}{l}\text { Centre } 2 \\
68\end{array}$ & $\begin{array}{l}\text { Centre } 3 \\
80\end{array}$ & $\begin{array}{l}\text { Total } \\
221\end{array}$ \\
\hline \multicolumn{5}{|l|}{ Implant characteristics } \\
\hline Mean duration of implant, years (range) & 11.8 years $(8-14)$ & 12.7 years $(3-30)$ & 17.7 years $(4-38)$ & 14.1 years \\
\hline Mean implant volume, cc (range) & 374.9 cc $(150-655)$ & 284.4 cc $(120-440)$ & 328.7 cc $(120-600)$ & $329.3 \mathrm{cc}$ \\
\hline \multicolumn{5}{|l|}{ Purpose of implantation $(n)$} \\
\hline - Reconstructive & $55 / 73(75 \%)$ & $26 / 68(38 \%)$ & $46 / 80(57 \%)$ & $127 / 221(57 \%)$ \\
\hline - Aesthetic & $18 / 73(25 \%)$ & $42 / 68(62 \%)$ & $34 / 80(43 \%)$ & $94 / 221(43 \%)$ \\
\hline \multicolumn{5}{|l|}{ Plane of augmentation } \\
\hline - Subglandular & $2 / 73(3 \%)$ & $38 / 68(56 \%)$ & $48 / 80(60 \%)$ & $88 / 221(40 \%)$ \\
\hline - Submuscular & $71 / 73(97 \%)$ & $30 / 68(44 \%)$ & $32 / 80(40 \%)$ & $133 / 221(60 \%)$ \\
\hline \multicolumn{5}{|l|}{ Implant shape } \\
\hline - Round & $32 / 73(44 \%)$ & $57 / 68(84 \%)$ & $39 / 80(49 \%)$ & $128 / 221(58 \%)$ \\
\hline - Anatomic & $39 / 73(53 \%)$ & $7 / 68(10 \%)$ & $34 / 80(42 \%)$ & $80 / 221(36 \%)$ \\
\hline •Unknown & $2 / 73(3 \%)$ & $4 / 68(6 \%)$ & $7 / 80(9 \%)$ & $13 / 221(6 \%)$ \\
\hline \multicolumn{5}{|l|}{ Implant type } \\
\hline - Single lumen & $61 / 73(84 \%)$ & $66 / 68(97 \%)$ & $70 / 80(87 \%)$ & $197(89 \%)$ \\
\hline - Double lumen & $12 / 73(16 \%)$ & $2 / 68(3 \%)$ & $10 / 80(13 \%)$ & $24(11 \%)$ \\
\hline \multicolumn{5}{|l|}{ Implant brand } \\
\hline - McGhan & $14 / 73$ & $20 / 68$ & $9 / 80$ & $43 / 221$ \\
\hline - Mentor & $29 / 73$ & $3 / 68$ & $15 / 80$ & $47 / 221$ \\
\hline • PIP & $2 / 73$ & $2 / 68$ & $0 / 80$ & $4 / 221$ \\
\hline - Laboratories Arion & $5 / 73$ & $0 / 68$ & $3 / 80$ & $8 / 221$ \\
\hline - Eurosilicone & $4 / 73$ & $0 / 68$ & $4 / 80$ & $8 / 221$ \\
\hline - Polytech & $1 / 73$ & $2 / 68$ & $6 / 80$ & $9 / 221$ \\
\hline - Inamed corporation & $5 / 73$ & $10 / 68$ & $0 / 80$ & $15 / 221$ \\
\hline - Silimed & $5 / 73$ & $2 / 68$ & $0 / 80$ & $7 / 221$ \\
\hline - Nagor & $3 / 73$ & $0 / 68$ & $2 / 80$ & $5 / 221$ \\
\hline - Allergan & $3 / 73$ & $19 / 68$ & $25 / 80$ & $47 / 221$ \\
\hline • Koken & $0 / 73$ & $0 / 68$ & $2 / 80$ & $2 / 221$ \\
\hline - Dow Corning & $0 / 73$ & $2 / 68$ & $0 / 80$ & $2 / 221$ \\
\hline - Sebin & $0 / 73$ & $0 / 73$ & $5 / 80$ & $5 / 221$ \\
\hline - Unknown & $2 / 73$ & $8 / 68$ & $9 / 80$ & $19 / 221$ \\
\hline \multicolumn{5}{|l|}{ Implant position } \\
\hline - Left & $41 / 73(56 \%)$ & $29 / 68(43 \%)$ & $26 / 80(33 \%)$ & $96 / 221(43 \%)$ \\
\hline - Right & $32 / 73(44 \%)$ & $39 / 68(57 \%)$ & $54 / 80(67 \%)$ & $125 / 221(57 \%)$ \\
\hline \multicolumn{5}{|l|}{ Main purpose of radiological investigation } \\
\hline - Follow-up/control & $38 / 62(61 \%)$ & $34 / 64(53 \%)$ & $31 / 57(54 \%)$ & $103 / 183(56 \%)$ \\
\hline - Pain/discomfort & $8 / 62(13 \%)$ & $9 / 64(14 \%)$ & $10 / 57(18 \%)$ & $27 / 183(15 \%)$ \\
\hline - Deformation/asymmetry/redness/swelling & $14 / 62(22 \%)$ & $17 / 64(26 \%)$ & $15 / 57(26 \%)$ & $46 / 183(25 \%)$ \\
\hline - Trauma & $2 / 62(4 \%)$ & $4 / 64(6 \%)$ & $1 / 57(2 \%)$ & $7 / 183(4 \%)$ \\
\hline \multicolumn{5}{|l|}{ Subject's reported symptoms during visit } \\
\hline - Asymptomatic & $14 / 62(22 \%)$ & $28 / 64(44 \%)$ & $23 / 57(40 \%)$ & $65 / 183(36 \%)$ \\
\hline - Pain/discomfort & $28 / 62(45 \%)$ & $19 / 64(30 \%)$ & $14 / 57(25 \%)$ & $61 / 183(33 \%)$ \\
\hline - Deformation & $16 / 62(26 \%)$ & $15 / 64(23 \%)$ & $17 / 57(30 \%)$ & $48 / 183(26 \%)$ \\
\hline - Redness & $4 / 62(7 \%)$ & $2 / 64(3 \%)$ & $3 / 57(5 \%)$ & $9 / 183(5 \%)$ \\
\hline \multicolumn{5}{|l|}{ Evaluation of implant integrity } \\
\hline Ultrasonography & $40 / 73(55 \%)$ & $27 / 68(40 \%)$ & $45 / 80(56 \%)$ & $112 / 221(51 \%)$ \\
\hline Magnetic resonance imaging & $25 / 73(34 \%)$ & $20 / 68(29 \%)$ & $13 / 80(16 \%)$ & $58 / 221(26 \%)$ \\
\hline Ultrasonography + magnetic resonance imaging & $8 / 73(11 \%)$ & $21 / 68(31 \%)$ & $22 / 80(28 \%)$ & $51 / 221(23 \%)$ \\
\hline
\end{tabular}


Table 2 (continued)

\begin{tabular}{|c|c|c|c|c|}
\hline $\begin{array}{l}\text { Hospital } \\
\text { Implants suspected of rupture }\end{array}$ & $\begin{array}{l}\text { Centre } 1 \\
73\end{array}$ & $\begin{array}{l}\text { Centre } 2 \\
68\end{array}$ & $\begin{array}{l}\text { Centre } 3 \\
80\end{array}$ & $\begin{array}{l}\text { Total } \\
221\end{array}$ \\
\hline \multicolumn{5}{|l|}{ Diagnosis of: } \\
\hline - Suspected intracapsular rupture & $59 / 73(81 \%)$ & $33 / 68(49 \%)$ & $46 / 80(56 \%)$ & $138 / 221(62 \%)$ \\
\hline - Suspected extracapsular rupture & $11 / 73(15 \%)$ & $32 / 68(47 \%)$ & $25 / 80(31 \%)$ & $68 / 221(31 \%)$ \\
\hline - Suspected intra-extracapsular rupture & $3 / 73(4 \%)$ & $3 / 68(4 \%)$ & $9 / 80(11 \%)$ & $15 / 221(7 \%)$ \\
\hline \multicolumn{5}{|l|}{ Findings at explantation } \\
\hline Number of implants with rupture at explantation & $44 / 73(60 \%)$ & $55 / 68(80 \%)$ & $49 / 80(61 \%)$ & $148 / 221(67 \%)$ \\
\hline Number of implants without rupture at explantation & $29 / 73(40 \%)$ & $13 / 68(20 \%)$ & $31 / 80(39 \%)$ & $73 / 221(33 \%)$ \\
\hline - US-suspected implants were found intact when explanted & $18 / 40$ & $7 / 30$ & $23 / 45$ & $48 / 115$ \\
\hline - RM-suspected implants were found intact when explanted & $9 / 25$ & $4 / 20$ & $5 / 13$ & $18 / 58$ \\
\hline - US+RM-suspected implants were found intact when explanted & $2 / 8$ & $2 / 18$ & $3 / 22$ & $7 / 48$ \\
\hline
\end{tabular}

however, the incidence of complications is known to be higher in revision surgery than in primary surgery.

We have therefore developed a decisional algorithm that should guide every surgeon in the diagnostic therapeutic process avoiding, or at least decreasing, the number of false positives (see Fig. 1).

This algorithm takes into account the reason for the investigation, the presence of symptoms, the use of ultrasound or MRI for the diagnosis and the psychological aspect of the patient.

The emotional picture of women diagnosed with a "suspected implant rupture" during a normal follow-up check (in most cases, therefore, asymptomatic) should not be underestimated as this can influence the diagnosis and, therefore, the subsequent therapeutic procedure [17].

Our multicentric study confirms how the psychological picture of the patient can influence the surgeon's decision on the diagnostic-therapeutic procedure to be undertaken [17]. In fact, although $56 \%$ of the patients had undergone a radiological examination for control/follow-up (so they are presumed to be asymptomatic) and only $15 \%$ for pain and discomfort, during the consultation with the plastic surgeon (following the radiological diagnosis), the symptoms complained of by the patients were pain and discomfort in $33 \%$, while only $36 \%$ of the patients reported no pain.

This increase in the number of symptomatic patients between the radiological investigation and the consultation with the plastic surgeon seems to be due to the onset of fear that turns into psychological pain; this pain, if it is not processed and persists, can somatise and turn into physical pain. All this can induce the surgeon to make a clear decision about prosthetic revision surgery.

Therefore, since many factors have to be taken into consideration in the diagnosis and treatment of these patients, it seems necessary (from a medical/legal point of view) to have a wide and exhaustive interview with the patient that allows her to receive correct and ample information in order to be able to make a judicious choice about the Evidence Base
Practice, a choice that is informed and not determined by the fear and emotions of the moment.

It is essential to submit to the patient an appropriate and specific informed consent form using Evidence Based Medicine (EBM) [19].

\section{A model of informed consent}

Given the absence in the literature of ad hoc consents for patients with suspected intracapsular implant rupture, we have drawn up a prospectus and consent form based on the results obtained and on what is present in the literature (see Annex 1).

This consent form has different sections: in the first part, there is an informed prospectus describing the advantages (and possible complications) of a watchful wait, i.e. carrying out close clinical-radiological checks.

Based on EBM, a watchful wait in asymptomatic patients appears justified. In fact, as Holmich et al. suggested, implant rupture is a harmless event that does not seem to produce significant clinical symptoms or activate the humoral immune system, and only in rare cases may give rise to severe local problems, at least within a period of 2 years [11]. So, their findings do not support the view that explantation surgery is mandatory in asymptomatic women. However, because there appears to be a small risk of progression of free silicone migration, they suggested that women with asymptomatic implant rupture be followed with regular clinical examinations, including evaluation of specific signs of silicone migration [11].

The second part describes the possible psychological consequences for patients with a diagnosis of suspected intracapsular implant rupture. The risks associated with the development of a somatoform disorder justify the need for psychological counselling; therefore, the possibility of an interview with expert psychologists is made available.

Finally, in the last part of the informed consent form, the other possible option is prosthetic revision surgery: from the 


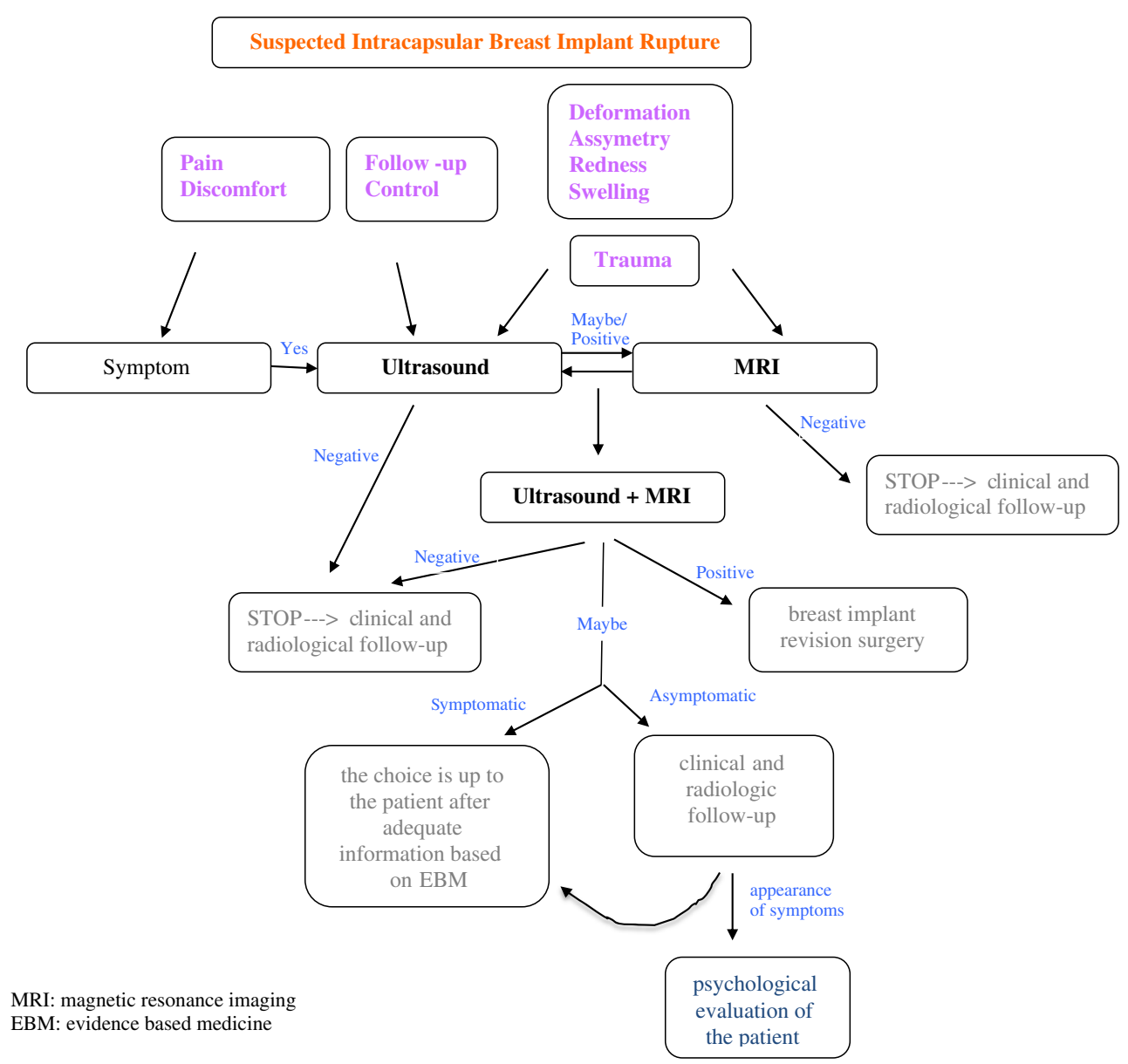

Fig. 1 Decision and management algorithm flowchart. Various reasons could lead the patient to carry out a radiodiagnostic check: for the onset of symptoms after a trauma, in asymptomatic patients for a normal check/ follow-up, for the onset of breast asymmetry, for the presence of other signs at breast level such as swelling and redness. Normally, asymptomatic patients were diagnosed with suspected rupture by ultrasound at a normal follow-up check. Patients with symptoms or following trauma underwent MRI directly. If this test does not confirm a frank rupture, it must be supplemented with another radiodiagnostic test. If the rupture is confirmed, prosthetic revision surgery will be indicated.

accurate description of the procedure to the possible related complications, emphasizing that the final aesthetic result may not meet expectations.

The current study is not exempt from limitations.

The limitations of this study are mainly represented by the retrospective design of the study; clinical and radiological evaluations are highly physician-dependent; all examinations were not performed at the same radiologic centre and all US and MRI images not were read by the same reader.

\section{Conclusions}

In the case of extracapsular rupture US diagnosis, surgical implant removal could be proposed without further investigations.
In the event that radiodiagnostic doubt remains and the patient is symptomatic, a doctor-patient interview associated with specific informed consent based on EBM will allow the patient to choose the procedure to follow. If the patient is asymptomatic, she will be advised to carry out radiodiagnostic checks every 6 months (or earlier if the clinical picture changes). If the patient complains of symptoms during subsequent examinations, it is advisable to recommend psychological counselling. Subsequently, a doctor-patient interview associated with a specific informed consent based on EBM will make the patient aware of the pros and cons of possible surgery

In case of intracapsular rupture, if US indicates a possible rupture, it should be investigated with MRI, which offers greater sensitivity. If doubt persists, it is of primary importance to inform the patient of the advantages/disadvantages of performing a close clinical radiological follow-up, as well as psychological counselling if considered useful.

Adequate informed consent, which is as broad and specific as possible, is necessary in this area, both to enable the patient to participate in the choice of therapeutic procedure, and to avoid possible legal disputes related to any complications resulting from unnecessary intervention.

\section{Compliance with ethical standards}

Funding This research did not receive any specific grant from funding agencies in the public, commercial, or not-for-profit sectors. 
Conflict of interest Nicola Zingaretti, Daniele Fasano, Franz W. Baruffaldi Preis, Carlo Moreschi, Silvia Ricci, Samuele Massarut, Francesco De Francescoa and Pier Camillo Parodi declare that they have no conflict of interest.

Ethical approval Our institutional ethics committee (Institutional Review Board IRB - DAME, Udine, Italy) approved the study design.

Informed consent A written informed consent was obtained from all patients in the study.

Open Access This article is licensed under a Creative Commons Attribution 4.0 International License, which permits use, sharing, adaptation, distribution and reproduction in any medium or format, as long as you give appropriate credit to the original author(s) and the source, provide a link to the Creative Commons licence, and indicate if changes were made. The images or other third party material in this article are included in the article's Creative Commons licence, unless indicated otherwise in a credit line to the material. If material is not included in the article's Creative Commons licence and your intended use is not permitted by statutory regulation or exceeds the permitted use, you will need to obtain permission directly from the copyright holder. To view a copy of this licence, visit http://creativecommons.org/licenses/by/4.0/.

\section{References}

1. Handel N, Cordray T, Gutierrez J, Jensen JA (2006) A long-term study of outcomes, complications, and patient satisfaction with breast implants. Plast Reconstr Surg 117:757-767 discussion 6872

2. ISAPS International Survey on Aesthetic/Cosmetic. Accessed August 2015. Available online: http://www.isaps.org/Media/ Default/global-statistics/2016\%20ISAPS\%20Results.pdf

3. Wazir U, Kasem A, Mokbel K (2014) A systematic review of the clinical impact of the PIP breast implants. Eur J Surg Oncol 40:S73

4. De Biasio F, Zingaretti N, De Lorenzi F, Riccio M, Vaienti L, Parodi PC (2017) Reduction mammaplasty for breast symmetrisation in implant-based reconstruction. Aesthet Plast Surg 41:773-781

5. Zingaretti N, Guarneri GF, De Biasio F, Shoeib MA, Parodi PC (2018) The use of meshed dermal autograft in breast reconstruction. Aesthet Plast Surg 42:1704-1706

6. Calabrese S, Zingaretti N, De Francesco F, et al. (2019) Long-term impact of lipofilling in hybrid breast reconstruction: retrospective analysis of two cohorts. In press

7. American Society of Plastic Surgeons. 2015 Plastic surgery statistics. Accessed August 2016. Available online: https://www. plasticsurgery.org/news/plastic-surgery-statistics?sub=2015+ Plastic+Surgery+Statistics

8. Center for Devices and Radiological Health. U.S. Food and Drug Administration. FDA update on the safety of silicone gel-filled breast implants June 2011;20, http://www.fda.gov/ downloads/MedicalDevices/ProductsandMedicalProcedures/ ImplantsandProsthetics/BreastImplants/UCM260090.pdf; June 2011 [accessed 18.02.12]

9. Zingaretti N, De Lorenzi F, Dell'Antonia F et al (2016) The use of precapsular space in secondary breast reconstruction. Aesthet Plast Surg 40:716-723

10. Berg WA, Caskey CI, Hamper UM, Anderson ND, Chang BW, Sheth S, Zerhouni EA, Kuhlman JE (1993) Diagnosing breast implant rupture with MR imaging, US, and mammography. Radiographics 13:1323-1336

11. Holmich LR, Vejborg I, Conrad C, Sletting S, McLaughlin JK (2005) The diagnosis of breast implant rupture: MRI findings compared with findings at explantation. Eur J Radiol 53:213-225

12. Lotan AM, Retchkiman M, Tuchman I, Binenboym R, Gronovich Y (2016) Analysis of 109 consecutive explanted breast implants: correlation between suspected implant rupture and surgical findings. Aesthet Plast Surg 40:739-744

13. Nathan B, Meleagros L, Mashhadi S, Lahoud P, Nash Z (2015) The breast implant rupture warranty: what is it really worth? Aesthet Plast Surg 39:826

14. Zingaretti N, Rampino Cordaro E, Marega G et al (2019) Determinants of surgeon choice of suspected breast implant rupture: a practical guide. Am J Forensic Med Path. In press

15. Di Benedetto G, Cecchini S, Grassetti L et al (2008) Comparative study of breast implant rupture using mammography, sonography, and magnetic resonance imaging: correlation with surgical findings. Breast J 14:532-537

16. Hillard C, Fowler JD, Barta R, Cunningham B (2017) Silicone breast implant rupture: a review. Gland Surg 6:163-168

17. Rietjens M, Villa G, Toesca A et al (2014) Appropriate use of magnetic resonance imaging and ultrasound to detect early silicone gel implant rupture in postmastectomy reconstruction. Plast Reconstr Surg 134:13e-20e

18. Chung KC, Malay S, Shuver MJ, Kim HJ (2012) An economic analysis of screening strategies for rupture of silicone gel implants. Plast Reconstr Surg 130:225-237

19. Azzena B, Casadei A, Fasano D et al Il consenso informato consapevole in chirurgia plastica estetica. New Magazine Edizioni, Trento

Publisher's note Springer Nature remains neutral with regard to jurisdictional claims in published maps and institutional affiliations. 